\title{
Afet Yönetimi Öğrencilerinin Empati Düzeyleri ile Kişilik Özellikleri Arasındaki İlişkiler: Gümüşhane Üniversitesi Örneği
}

\author{
The Relationship Between Empathy Levels and Personality Traits of Disaster \\ Management Students: The Case of Gümüşhane University
}

Öz

$\mathrm{Bu}$ araştırmanın amacı ilerleyen zamanlarda arama kurtarma faaliyetinde bulunacağı beklenen Acil Yardım ve Afet Yönetimi bölümünde öğrenim gören öğrencilerin empati düzeylerinin belirlenmesi ve kişilik özellikleri ile empati düzeyleri arasındaki ilişkinin tespit edilmesidir. Bu amaçla, araştırmamızın evrenini Gümüşhane Üniversitesi Acil Yardım ve Afet Yönetimi Bölümünde öğrenim gören öğrenciler oluşturmaktadır. Kolayda örnekleme yöntemiyle belirlenen bir örneklem üzerinde, internet üzerinden anket yöntemiyle bir araştırma yapılmıştır. Araştırmada frekans, bağımsız örneklem T-testi, ANOVA ve korelasyon analizi kullanılmıştır. Öğrencilerin empati düzeylerine bakıldı̆̆ında bilişsel empati skorlarının hem $\mathrm{klz}$ hem de erkek ögrrencilerde iyi düzeyde ve birbirine yakın ortalamalara sahip olduğu tespit edilmiştir. Duygusal empati düzeyleri incelendiğinde ise cinsiyete göre fark olduğu ve kız öğrencilerin erkek ögrrencilere göre daha yüksek ortalamaya sahip oldukları saptanmıştır. Kişilik özellikleri ile empati düzeyleri arasındaki ilişki incelendiğinde bilişsel empati ile sirasıyla zekâ/hayal gücü ve uyumluluk kişilik özellikleri arasinda orta düzeyde, sorumluluk kişilik özelliği arasında ise düşük düzeyde anlamlı ve pozitif yönlü bir ilişki olduğu tespit edilmiştir. Duygusal empati ile duygusal dengelilik kişilik özelliği arasında orta düzeyde ve uyumluluk kişilik özelliği ile de düşük düzeyde anlaml ve pozitif yönlü bir ilişki

Mazhar Oyanık

Dr., Gümüşhane Üniversitesi, moyanik@gumushane.edu.tr, Orcid: https://orcid.org/0000-0003-0437-9436

Article Type / Makale Türü

Research Article / Araştırma Makalesi

Anahtar Kelimeler

Bilişsel Empati, Duygusal Empati, Empati

Düzeyi, Kişilik Özellikleri ile Empati

Düzeyleri Arasındaki İlişkiler

Keywords

Cognitive Empathy, Emotional Empathy, Empathy Level, The Relationships Between

Personality Traits and Empathy Levels

Submitted: $\quad 14 / 03 / 2021$

Accepted: $\quad 31 / 03 / 2021$ bulunmuştur.

\section{Abstract}

The aim of this study is to determine the empathy levels of the students studying in the Emergency Aid and Disaster Management department, which is expected to carry out search and rescue activities in the future, and to determine the relationship between personality traits and empathy levels. For this purpose, the universe of our research consists of the students studying in the Emergency Aid and Disaster Management Department of Gumushane University. A research was conducted on a sample determined by convenience sampling method using the online survey method. Frequency, independent sample T-test, ANOVA and correlation analysis were used in the study. When the empathy levels of the students were examined, it was found that the cognitive empathy scores of both female and male students were at a good level and close to each other. When emotional empathy levels were examined, it was found that there was a difference according to gender and that female students had a higher average than male students. When the correlation between personality traits and empathy levels was examined, it was found that there was a moderate correlation between cognitive empathy and intelligence / imagination and compatibility personality trait, and a low level of significant and positive correlation between responsibility personality trait. It was found that there was a moderate correlation between emotional empathy and emotional stability personality trait, and a low level of significant and positive correlation also with the compatibility personality trait.

\section{Giriş}

Ülkemiz afet çeşitliliği bakımından zengindir. Bu afetlerin oluş biçimleri ve mağduriyet yaşatmaları ise kaçınılmaz sonuçları da beraberinde getirmektedir. Deprem, sel, çı̆̆ gibi hem doğal yaşamı alt üst eden hem de bireysel ve ekonomik mağduriyetler oluşturan afetler sonrasında aramakurtarma faaliyetleri önem arz etmektedir. Bir afete maruz kalmış birinin mağduriyet yaşamasından 
normal hayata döndürülmesi süreci arama-kurtarma faaliyetlerini kapsamaktadır. Bu bağlamda bir afete maruz kalmış bireyin mağduriyetinin en kısa ve en etkili yöntemlerle giderilmesi aramakurtarma faaliyetlerine katılan ekiplerden beklenmektedir. Gelişen teknoloji sayesinde robotlaşmaya gittiğimiz günümüzde deprem enkazından kurtarma çalışmalarına artık robotlarda kullanılmaktadır. Bunun yanı sıra eğitimli ve kokuya duyarlı arama-kurtarma köpekleri de yardımcı olmaktadır. Fakat ne robotlar ne de yardım için kullanılan hayvanlar mağdur kişinin durumu ile ilgili empati yapma yetenekleri bulunmamaktadır. Empati kurma düşünme kabiliyetine sahip insanoğlunun özelliğidir. Arama-kurtarma çalışmalarına katılan ekiplerin empatik davranışlar sergilemesi mağduriyet yaşayan bireylere daha hızlı müdahalelerle ulaşabilme yetisi kazandırabilir ve mağdur kişi ile iletişimde daha verimli sonuçlar verebilir. Nitekim literatür çalışmalarında empatik olan hekimlerin hastaların iyileşme süreçlerini hızlandırdığı ve verimli sonuçlar alındığı tespit edilmiştir. Aynı şekilde bir enkaz altında varlığına ulaşılabilinen bireylerin en kaz altında yaşam ile ölüm arasında geçen sürelerinde arama-kurtarma ekipleri empatik davranarak mağdur kişinin direnç seviyelerini yükseltebilir aynı zamanda daha verimli ve daha süratli çalışmalar gerçekleştirebilir. Çalışmamızda ilerleyen yaşamlarında acil yardım müdahalelerinde bulunması beklenen Gümüşhane Üniversitesi Acil Yardım ve Afet Yönetimi bölümü öğrencilerinin empati düzeyleri ve kişilik özellikleri arasındaki ilişki incelenmiştir.

\section{Literatür}

\subsection{Empati Kavramı}

Empati kavramı, insanların sosyal doğasını karakterize eden iki temel özelliğin felsefi ve psikolojik tartışmalarında ve araştırmalarında merkezi bir rol oynamıştır ve oynamaya devam etmektedir. Bu kavram yalnızca yirminci yüzyılın başında icat edilmiş olmasına rağmen 17. ve 18 . Yüzyıl İngiliz filozoflarınca, özellikle David Hume'dan beri sempati başlı̆̆1 altında ilgi odağ1 olmuştur. Bu konuda Adam Smith ahlaki yargiların, ahlaki motivasyonun ve insanların sosyal doğasının psikolojik temelini analiz etmeye çalışmıştır (Stueber, 2013: 1).

Empati terimi yaklaşık 100 yıl önce, Almanca "Einfühlung" kelimesinin bir uyarlaması olarak Titchener (1909) tarafından literatüre kazandırılmıştır (Cuff vd., 2016: 144). Titchener (1909) "Einfiihlung" kelimesini "nesneleri insanlaştırma, kendimizi onlara okuma veya hissetme süreci" olarak yorumlamıştır ve psikolojideki empati teorileri büyük ölçüde bu görüşten etkilenerek geliştirilmiştir. Bazı teorisyenler empatiyi bir kişilik özelliği veya genel yetenek olarak adlandırmışlar ve bir özellik veya başka bir kişinin iç deneyimini bilme veya diğer insanların duygularını hissetme yeteneği olarak kavramsallaştırmışlardır. Empatinin bir özellik veya sabit bir yetenek olduğunu psikanalitik teorisyenler, psikoterapi araştırmacıları ve sosyal ve gelişimsel psikologlar desteklemişlerdir (Duan ve Hill, 1996: 261-262).

Empati terimi ile ilgili uzun zamandır devam eden açık ve üzerinde anlaşılmış bir tanımın olmaması sayısız zorluğa neden olmuştur. Halk arasında empati, "kendini başkalarının yerine koyma" olarak mecazi anlamda bilinir. Bununla birlikte, bilimsel alanda terimin evrensel bir tanımı yoktur. Kısaca başkasının duygularını algılama ve bu anlayışı iletme, anlaşıldığını hissetmelerine yardımcı olma yeteneği olarak tanımlanır (Bas-Sarmiento vd., 2020: 1).

Empati genellikle, başka bir kişinin içsel deneyimini, o kişiden onun düşünceleri veya duyguları hakkındaki ipuçlarını zorunlu olarak algılamadan bilme, doğuştan etkiye sahip, indirgenemez bir doğuştan gelen kapasite olarak kabul edilir. Buna karşın empati yoluyla başka bir kişi hakkında edinilebilecek bilgiler, düşünceler ve duygular sınırlıdır (Buie, 1981: 305).

Farklı bir empati tanımlaması da Cuff vd. (2016) tarafından yapılmıştır. Çalışmalarında çeşitli filozof ve teorisyenlerin yapmış oldukları 43 farklı empati tanımını incelemişlerdir. Çalışmaları sonucunda; empati ile ilgili kavramlar arasında işlevsel farklılıklar vardır; empati hem bilişsel hem de duyuşsal öğeleri içerir; hedefin ve gözlemcinin duyguları benzerdir ancak aynı değildir; hayal gücü gibi diğer uyaranlar empati uyandırabilir; empatide kendi / diğer ayrımı korunur, ancak bir dereceye kadar birleştirme gereklidir; empati hem özellik hem de durum etkilerinden etkilenir; davranışsal sonuçlar empatinin bir parçası değildir; ve son olarak, empati otomatik olarak ortaya çıkar, ancak yukarıdan aşağıya kontrollü süreçlere de tabidir. Empati, özellik kapasiteleri ve durum 
etkileri arasındaki etkileşime bağlı olan duygusal bir tepkidir (duygusal empati). Empatik süreçler otomatik olarak ortaya çıkarılır, ancak yukarıdan aşağıya kontrol süreçleriyle de şekillendirilir. Ortaya çıkan duygu, kişinin uyaran duyguyu algılamasına (doğrudan deneyimlenen veya hayal edilen) ve anlayışına (bilişsel empati) benzerdir ve duygunun kaynağının kişinin kendi olmadığını kabul eder (Cuff vd., 2016:150). Bilişsel empati, zihinsel ve bilişsel işlevleri içerir ve bir başkasının duygularını ve bakış açısını yorumlama ve anlama kapasitesidir. Bilişsel empatinin tersine, duygusal empati, bir başkasının acısını veya sıkıntısını deneyimlemeyi ve hissetmeyi içeren nispeten sabit bir içsel özelliktir. Aşırı duygusal empati, mağduru olumsuz etkileyebilir ve şefkat yorgunluğuna ve tükenmişliğe yol açabilirken, aşırı bilişsel empati ise zararlı değildir (Williams vd., 2020: 312).

Empati, ahlaki, bilişsel, duygusal ve davranışsal bileşenleri olan karmaşık, çok boyutlu bir kavramdır. Morse tarafından empati üzerine literatürün kapsamlı bir incelemesi, empatinin bileşenlerini dört temel alan altında Tablo 1.'de gösterilmiştir (Mercer ve Reynolds, 2002: 9).

Tablo 1. Morse'nun Empati Bileşenleri

\begin{tabular}{ll}
\hline Bileşen & Tanım \\
\hline Duygusal & $\begin{array}{l}\text { Başkasının psikolojik durumunu veya içsel duygularını öznel olarak } \\
\text { deneyimleme ve paylaşma yeteneği }\end{array}$ \\
Ahlaki & $\begin{array}{l}\text { Empati pratiğini motive eden içsel başkalarını düşünen bir güç } \\
\text { Bilişsel }\end{array}$ \\
Başka bir kişinin duygularını ve bakış açısını objektif bir duruştan tanımlama \\
ve anlama yeteneği
\end{tabular}

Kaynak: Mercer, S. W., ve Reynolds, W. J. (2002). Empathy and quality of care. British Journal of General Practice, 52(Suppl), 9-12.

Fakat empati araştırmacılarının çoğu, empatinin duygusal bulaşmanın en temel düzey biçimi olduğunu düşünmektedir. Duygusal bulaşma, psikolog Elaine Hatfield, John Cacioppo ve Richard Rapson tarafından "ifadeleri, seslendirmeleri, duruşları ve hareketleri başka bir kişininkilerle otomatik olarak taklit etme, senkronize etme ve sonuç olarak duygusal olarak yakınlaşma eğilimi" olarak tanımlanmaktadır. Fakat duygusal bulaşma ile empati önemli ölçüde farklı olgulardır (Coplan, 2011: 45). Empati olması için üç ana işlevsel bileşenin ("kendi ve öteki arasında duygusal paylaşım, *kendinin farkında olma/öz farkındalık, *diğerinin öznel bakış açısını benimseyebilmek için zihinsel esneklik) birbirleriyle etkileşime girmeleri gerekiyor. Örneğin, öz farkındalık olmadan duygu paylaşmak, "birinin duyguları ile diğerinin duyguları arasında ayrım yapılmaksızın tam özdeşleşme" biçimi duygusal bulaşma olgusunu ifade eder (Decety ve Jackson, 2004: 75). Duygusal bulaşma, birlikte olduğumuz başkalarının duygularını aldığımızda ortaya çıkar. Örneğin mutlu insanlarla dolu bir odada mutlu olduğumuzda veya birlikte olduğumuz insanlar arasinda bir panik çıktığında panikleriz. Duygusal bulaşmada, diğer kişilerin sahip olduğu duyguyu yakalarız, ancak bu gerçeğin mutlaka farkında olmayız ve diğer kişilere özellikle odaklanmayız veya onlarla ilgilenmeyiz. Fakat duygusal empatide, diğer kişiyle sadece benzer bir duyguyu paylaşmayız veya onun durumuna bizimkinden daha uygun olan bir duyguya sahip değilizdir (Stueber, 2013: 5).

\subsection{Empatinin Önemi}

Empati, başka bir kişinin diğer kişinin referans çerçevesi içinde ne deneyimlediğini anlama kapasitesidir, yani kendini başkasının yerine koyma kapasitesidir. Empatik etkileşimin özü, başka birinin duygularını doğru anlamaktır (Bellet ve Maloney, 1991: 1831). Empati, sosyal hayatta etkili iletişimin kurulmasını kolaylaştıran kişilerarası davranışların temel özelliklerinden biridir. Aslında sosyal yaşam ve grup faaliyetleri, grup üyeleri arasında empatiyi gerektirir. Empati, insani davranışları, ahlaki kararları, personel performansını ve müşteri memnuniyetini önemli ölçüde etkilediği için kuruluşların işlevi için de gereklidir (Montazeri vd., 2020: 337). Empati, diğerinin acısı veya rahatsızlığındaki kişisel sıkıntıyı yatıştırmak için kullanılan bir duygu düzenleme sürecidir ve 
diğerine merhamet ve yardım davranışını harekete geçirmeyi mümkün kılar. Bu, ötekinin özel algısal dünyasına girmek anlamina gelir (Elliott vd., 2011: 43-44).

Literatür incelendiğinde empatinin önemi ile ilgili sağlık alanlarında çalışmalara rastlanmaktadır. Özellikle tıpta empati, hekimlerde arzu edilen bir özelliktir ve hekim-hasta ilişkisinin önemli bir unsurudur. Sağlık alanında hasta-hekim iletişimi sırasında şefkat ve empati, sağlık sorunlarının başarılı bir şekilde tedavi edilmesinin ana bileşenleridir. Bu nedenle empatik hekimlerin daha iyi hasta-hekim ilişkisi, hasta güveni, memnuniyeti, uyumu üretme ve klinik uygulamalarda daha iyi sonuçlar elde etme olasılığı daha yüksektir (Abe ve vd., 2018: 2). Empatik hekimlerin hasta memnuniyeti, doktora güven, tedaviye uyum ve klinik sonuçlar üzerinde olumlu bir etkisi vardır. Empati, hastaların duygularını anlamakla ilgilidir ve şaşırtıcı olmayan bir şekilde, anlaşıldığını hisseden hastaların semptomlarını tam olarak açıklaması ve hasta-hekim ilişkisine girme olasılıkları daha yüksektir. Tıp eğitimi literatüründe empatinin çoklu tanımları, empatiyi bilişsel (hastanın duygularını anlama ve anlayışı hastalara geri iletme) ve duygusal boyutlar (hastanın duygularına duygusal tepkilerin bir karışımı) olarak karakterize eder (Costa vd., 2014: 1). Empati, pozitif bir ilişki işlevine hizmet eder. Hastaların daha üretken düşünmelerine yardımcı olur, üretken deneyim seviyelerini yükseltir, katılımını ve sürece açıklığı teşvik ederek buna katkıda bulunur. Kişinin mağdur için uyumlu müdahaleleri seçmesine yardımcı olur (Greenberg vd., 2001: 382-383). Mağdur kişiler, kendilerine yardımcı olacak kişilerin duygularını anladığını hissettiklerinde, bu mağdurların güvenini arttırır ve onları kendilerine yardımcı olacak kişilere karşı konuşmaya teşvik eder (Bellet ve Maloney, 1991: 1831).

\subsection{Kişilik Özelliklerinin Belirlenme Süreci}

İlk kişilik tiplerinin rasyonel bir sınıflandırmasını yapan Thurstone (1934) insanların mizaçları ve tavırları ile ilgili yaygın olarak kullanılan ve eş anlamlıları ile birlikte 120 sıfattan oluşan bir liste hazırlayarak beş faktörün yeterli olduğunu bulmuştur (Thurstone,1934: 1-32). Kişilik ile ilgili olabilecek İngilizce kelimeler üzerinde araştırma yapan Allport ve Odbert (1936) ise 400.000 adet terim ve kelimeler üzerinde çalışarak 17,953 adet kişilik ile ilgili kelime belirlemişlerdir (Allport ve Odbert, 1936: i-171). Kişilik ile ilgili bir başka sınıflandırma yapan Cattell (1947) 18.000 adet kelime belirleyerek eş anlamlı olanlarını göz ardı etmiş ve 35 tane kişilik özelliği ortaya koymuştur ve bunları 11 faktör altında toplamıştır (Cattell, 1947: 197-220). Cattell'in kişilik özelliklerini gruplandıran Norman (1963) dişadönüklük, uyumluluk, sorumluluk, duygusal dengelik ve kültürden oluşan beş faktör bulmuştur (Norman, 1963:574). 1970'lerde ortaya çıkardıkları NEO Kişilik Envanteri (NEO Personality Inventory-(NEO-PI)) ölçeğini revize eden Costa ve McCrae (2008) nevrotiklik, dışadönüklük ve açıklık faktörlerinin yanına 1987' de uyumluluk ve sorumluluk faktörlerini ekleyerek beş faktör modelini (FFM) ortaya çıkarmışlardır (Costa ve McCrae, 2008). Daha önceki çalışmalarda belirlenen beş faktör kişilik modelllerini "lexical hypothesis" (ilk kez Sir Francis Galton tarafından ortaya çıkarılan ve her biri ayrı bir anlam içeren ve karakteri belirten bin kelimeden oluşan sözcüklerdir. Büyük Beş Kişilik (big-five) faktör modeli bu varsayımdan esinlenerek geliştirilmiştir) çalışmasıyla yeniden belirleyen Goldberg (1990) büyük beş faktör olarak isimlendirdiği dışadönüklük, uyumluluk, sorumluluk, duygusal dengelik (nevrotikliğin karşıtı), deneyime açıklık/zeka faktörlerini belirlemiştir (Goldberg, 1990: 1216).

Son otuz yılda, en üst düzeyde, kişilik özellik farklılıklarının iyi bir şekilde özetlendiği konusunda genel bir fikir birliği olan beş büyük faktör ortaya çıktı: nevrotiklik (üzgün, gergin, kayıtsız, rahat, karamsar, kıskanç, mizaçlı, kıskanç, dokunaklı, huysuz), dışa dönüklük (sıcaklık, girişkenlik, aktivite, heyecan arayan, olumlu duygular konuşkan, dişa dönük, cesur, enerjik, utangaç, sessiz, çekingen, içine kapanık), deneyimlere açıklık / zeka (yaratıcı, yaratıcı, felsefi, entelektüel), uyumluluk (güven, açık sözlülük, fedakarlık, uygunluk, alçakgönüllülük, şefkatli olma, sempatik, sıcak, kibar, işbirlikçi, soğuk, anlayışsız, kaba, sert) ve sorumluluk (yetkinlik, düzen, görev bilinci, başarı çabası, öz disiplin, müzakere) (Mooradian vd., 2011: 100). Bu yapı, yaşam süresi boyunca, anketler ve sözcüksel paradigmalar arasında, değerlendiriciler arasında ve kültürler arasında ortaya çıkar; davranışlar, duygusal deneyimler ve bilişsel süreçlerle ilişkilendirilmiştir (Erlanger ve Tsytsarev, 2012: 23). 


\subsection{Literatürde Empati ve Kişilik İlişkisi}

Literatürde yapılan çalışmalarda kişilik özellikleri ile empati arasında ilişkilerin olduğu tespit edilmiştir. Yapılan çalışmalara göre nevrotiklik ile empati arasında yüksek derecede pozitif ilişki vardır (Daane ve Schmidt, 1957: 131), empatisi düşük olanlar, kontrolsüz duygusallık patlamalarına maruz kalan oldukça katı, içine kapanık insanlardır (Dymond, 1950: 349). Magalhães vd. (2012) tıp öğrencileri ile yaptıkları çalışmada empati ile deneyime açıklık ve uyumluluk kişilik özellikleri arasında pozitif yönlü, nevrotiklikle negatif yönlü bir ilişki ortaya çıkmıştır. Uyumlu ve deneyime açık öğrencilerin daha empatik olma eğiliminde oldukları saptamışlardır (Magalhães vd., 2012: 810). Abe vd. (2018) tıp öğrencileri üzerinde yaptıkları çalışmalarında nevrotiklik ve sorumluluk kişilik özellikleri ile empati arasında ilişki bulamamışlardır. Fakat empati ile dışadönüklük ve uyumluluk kişilik özellikleri arasında zayıf, deneyimlere açıklık/ zekâ arasında çok zayıf ilişki tespit etmişlerdir. Kişiliğin öğrencilerin empatik algılarını etkilediğini saptamışlardır (Abe vd., 2018:6). Nettle (2007), uyumluluk ve dişadönüklüğün empati ile yüksek ve anlamlı şekilde pozitif ilişkili olduğunu belirlemiştir (Nettle, 2007: 240). Melchers vd. (2016) dört farklı ülke (Çin, Almanya, İspanya, ABD) vatandaşları ile empati ile kişilik arasındaki ilişkiyi araştırdıkları çalışmalarında sadece uyumluluk faktörünün dört ülkede de empati ile yüksek ve pozitif ilişki olduğunu tespit etmişlerdir (Melchers vd., 2016: 2). Mooradian vd. (2011) empati ile deneyimlere açıklık/zekâ, uyumluluk ve nevrotiklik kişilik özellikleri arasında pozitif ilişki olduğunu saptamışlardır (Mooradian vd., 2011: 104-105). Portekiz'de tıp fakültesi öğrencileri üzerinde yapılan çalışmada uyumluluk ve deneyimlere açık/zekâ ile empati arasında pozitif ilişki çıkmıştır (Costa vd., 2014: 3-4). ABD’de özel bir tıp okulunda öğrenciler üzerinde yapılan çalışmada ise empati ile sosyallik ve saldırganlık-düşmanlık arasında düşük ve anlamlı ilişki bulunmuştur (Hojat vd., 2005: 1211).

\section{5. Ölçek}

Literatür çalışmasında araştırmalarda kullanıldığı tespit edilen ölçekler Tablo 2.'de sunulmuştur.

Tablo 2. Literatürde Kullanılan Ölçekler

\begin{tabular}{ll}
\hline Empati Ölçeği & Madde \\
\hline Derecelendirme Testi (Dymond, 1950) & $\begin{array}{l}6 \text { madde } \\
\text { Bilişsel empati } 20 \\
\text { madde }\end{array}$ \\
Jefferson Hekim Empati Ölçeği (Abe vd., 2018; Costa vd., 2014; Hojat vd., 2005) & $\begin{array}{l}\text { Bilişsel ve duygusal } \\
\text { empati } 60 \text { madde } \\
\text { Bilişsel ve duygusal } \\
\text { Baron-Cohen Empati } 28 \text { madde }\end{array}$ \\
Davis Kişilerarası Reaktivite Endeksi (IRI) (Melchers vd., 2016; Mooradian vd., 2011) & Madde \\
\hline Kişilik Ölçeği & 35 madde \\
\hline Zuckerman - Kuhlman Kişilik Anketi (ZKPQ, kisa form) (Hojat) vd.,2005) & 60 madde \\
Costa ve McCrae (1992) NEO Beş Faktör Envanteri (NEO FFI) (Melchers vd., 2016; Costa \\
vd., 2014; Mooradian vd., 2011)
\end{tabular}

Vossen vd. (2015) ergenlerde bilişsel empati, duygusal empati ve sempatiyi ölçen AMES ölçeğini geliştirmişlerdir (Vossen vd., 2015: 66-71). Duygusal ve bilişsel empati üzerindeki vurguyu dengeleyen bir ölçme aracı olduğu için araştırmamızda bu ölçek tercih edilmiştir.

\section{Araştırma}

\subsection{Araştırmanın Amacı ve Önemi}

$\mathrm{Bu}$ araştırmanın amacı ileriki yaşamlarında arama kurtarma faaliyetinde bulunacağı beklenen Acil Yardım ve Afet Yönetimi bölümünde öğrenim gören öğrencilerin empati düzeylerinin ve kişilik özellikleri ile empati düzeyleri arasındaki ilişkinin belirlenmesidir. Araştırmanın önemi ise arama kurtarma faaliyetinde bulunacak personelin seçiminde empatik davranış ile uyumlu kişilik yapısına sahip bireyler tercih edilebilir. Ayrıca empati ile arasında ilişkinin olmadığı kişilik özelliklerine sahip personelin empati eğitimleri ile empatik davranışları geliştirilebilir. 


\subsection{Araştırmanın Kapsamı ve Yöntemi}

Araştırmamızda kolayda örneklem yöntemi kullanılmıştır. Gümüşhane Üniversitesi Acil Yardım ve Afet Yönetimi bölümünde öğrenim gören gündüz ve gece bölümü öğrencileri toplamı 409'dur. Sosyal medya araçları yardımıyla ulaşabildiğimiz 158 öğrenciyle anket çalışması yapılmıştır. Doldurulan anketlere eksik ve hata tespit edilmemiştir. Tüm cevaplar analize dahil edilmiştir.

\subsection{Araştırmanın Kisıtlilıkları}

Zaman ve maliyet kısıtından dolayı araştırmamızın evreni Gümüşhane Üniversitesi Acil Yardım ve Afet Yönetimi bölümünde öğrenim gören öğrenciler olarak belirlenmiştir. Araştırmamız Türkiye'nin tamamını kapsayacak şekilde genellenemez. Ayrıca anketimiz COVID-19 pandemisinden dolayı yüz yüze yöntemle yapılamamıştır.

\subsection{Araştırmada Veri Toplama Araçları ve İstatiksel Yöntemler}

Araştırmamızda Vossen vd. (2015) tarafından geliştirilen Ergenlerde Empati ve Sempati ölçeğinin (AMES) bilişsel ve duygusal empati ölçeği kısmı kullanılmıştır. 4 soru bilişsel empatiyi ve 4 soru duygusal empatiyi ölçmektedir. Kişilik ölçeği olarak ise Oyanık (2020) tarafından uyarlanan 42 maddelik Beş Faktör Kişilik ölçeği kullanılmıştır. Anketler sosyal medya araçları ile kişilere ulaştırılmış olup 3 bölümden oluşmaktadır. Birinci bölümde demografik özellikler kategorik sorularla (3 soru), ikinci bölümde empati düzeyleri 5' li Likert tipi sorularla (8 soru) ve üçüncü bölümde ise kişilik özellikleri 5’li Likert tipi sorularla (25 soru) ölçülmeye çalışılmıştır.

\subsection{Araştırma Hipotezleri}

Araştırmamızda yapılan literatür çalışmalarına dayanarak hipotezler geliştirmiştir. Bu hipotezlerin geçerlilikleri çalışmamızda test edilmiş ve sonuçlar tartışılmaya çalışılmıştır.

H1: Öğrencilerin empati düzeyleri ile cinsiyetleri arasında fark vardır.

H1a: Öğrencilerin bilişsel empati düzeyleri ile cinsiyetleri arasında fark vardır.

H1b: Öğrencilerin duygusal empati düzeyleri ile cinsiyetleri arasında fark vardır.

$\mathrm{H} 2$ : Öğrencilerin sınıfları ile empati düzeyleri arasında fark vardır.

H2a: Öğrencilerin sınıfları ile bilişsel empati düzeyleri arasında fark vardır.

H2b: Öğrencilerin sınıfları ile duygusal empati düzeyleri arasında fark vardır.

H3: Öğrencilerin yaşları ile empati düzeyleri arasında fark vardır.

H3a: Öğrencilerin yaşları ile bilişsel empati düzeyleri arasında fark vardır.

$\mathrm{H} 3 b$ : Öğrencilerin yaşları ile duygusal empati düzeyleri arasında fark vardır.

H4: Öğrencilerin kişilik özellikleri ile empati düzeyleri arasında ilişki vardır.

H4a: Öğrencilerin kişilik özellikleri ile bilişsel empati düzeyleri arasında ilişki vardır.

H4b: Öğrencilerin kişilik özellikleri ile duygusal empati düzeyleri arasında ilişki vardır.

\section{Bulgular}

Tablo 3. Demografik Bulgular

\begin{tabular}{|c|c|c|c|c|}
\hline Özellik & Dağılım & Frekans & Yüzde & Kümülatif Yüzde \\
\hline \multirow{2}{*}{ Cinsiyet } & Kadın & 112 & 70,9 & 70,9 \\
\hline & Erkek & 46 & 29,1 & 100,0 \\
\hline \multirow{4}{*}{ Yaş } & 18 & 3 & 1,9 & 1,9 \\
\hline & 19 & 11 & 7,0 & 8,9 \\
\hline & 20 & 40 & 25,3 & 34,2 \\
\hline & 21 ve üzeri & 104 & 65,8 & 100,0 \\
\hline \multirow{4}{*}{ Sinif } & 1.sinif & 39 & 24,7 & 24,7 \\
\hline & 2.sinif & 41 & 25,9 & 50,6 \\
\hline & 3.sinif & 42 & 26,6 & 77,2 \\
\hline & 4.sinif & 36 & 22,8 & 100,0 \\
\hline
\end{tabular}


Araştırmamızda katılımcıların cinsiyetleri bakımından \% 70,9' u kız öğrenci (112 kişi) ve \% 29,1'i erkek öğrencidir (46 kişi). Yaş düzeylerinde, \% 1,9'u 18 yaşında (3 kişi), \% 7,0'1 19 yaşında (11 kişi), \% 25,3' ü 20 yaşında (40 kişi) ve \% 65,8'i 21 yaş ve üzerindedir (104 kişi). Sinıf düzeylerinde ise \% 24,7' si 1. sınıf öğrencisi (39 kişi), \%25,9'u 2. sınıf öğrencisi (41 kişi), \%26,6's1 3. sınıf öğrencisi (42 kişi) ve $\% 22,8^{\prime} i$ son sınıf öğrencisidir (36 kişi).

Tablo 4. Cinsiyete Göre Empati Düzeyleri

\begin{tabular}{|c|c|c|c|c|}
\hline \multicolumn{2}{|c|}{ Gruplar } & \multirow{2}{*}{$\begin{array}{c}\mathrm{N} \\
112\end{array}$} & \multirow{2}{*}{$\frac{\bar{X}}{3.78}$} & \multirow{2}{*}{$\frac{\text { Standart Sapma }}{0.57}$} \\
\hline Dil: 1 Imnt: & Kadın & & & \\
\hline 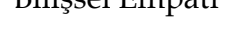 & Erkek & 46 & 3.81 & 0.55 \\
\hline \multirow{2}{*}{$\begin{array}{c}\text { Duygusal } \\
\text { Empati }\end{array}$} & Kadın & 112 & 3.26 & 0.63 \\
\hline & Erkek & 46 & 2.99 & 0.53 \\
\hline \multirow{2}{*}{ Toplam Empati } & Kadın & 112 & 3.52 & 0.47 \\
\hline & Erkek & 46 & 3.40 & 0.38 \\
\hline
\end{tabular}

Tablo 5. Bilişsel Empati Düzeyinin Cinsiyete Göre Farkı

\begin{tabular}{lcccccc}
\hline \hline Gruplar & $\mathrm{N}$ & $\overline{\mathrm{X}}$ & $\mathrm{Ss}$ & $\mathrm{Sd}$ & $\mathrm{t}$ & $\mathrm{p}$ \\
\hline Kadın & 112 & 3.78 & 0.57 & 156 & 0.268 & 0.79 \\
Erkek & 46 & 3.81 & 0.55 & & & \\
\hline \hline
\end{tabular}

Tablo 6. Duygusal Empati Düzeyinin Cinsiyete Göre Fark1

\begin{tabular}{ccccccc}
\hline \hline Gruplar & $\mathrm{N}$ & $\overline{\mathrm{X}}$ & $\mathrm{Ss}$ & $\mathrm{Sd}$ & $\mathrm{t}$ & $\mathrm{p}$ \\
\hline Kadın & 112 & 3.26 & 0.63 & 156 & 2.583 & 0.01 \\
Erkek & 46 & 2.99 & 0.53 & & & \\
\hline \hline
\end{tabular}

Tablo 4.' de cinsiyetlere göre öğrencilerin empati düzeyleri gösterilmiştir. Bulunan sonuca göre bilişsel empati düzeylerin kız ve erkek öğrencilerde yüksek ortalamaya sahipken duygusal empatide hem kız hem de erkek öğrencilerde orta seviye ortalamaya sahiptir. Empati düzeyleri ortalamalarının cinsiyete göre istatiksel olarak anlamlı fark olup olmadığını tespit edebilmek için bağımsız örneklem T-testi uygulanmıştır. Tablo 5.'te bilişsel empati düzeyi ortalamalarında cinsiyete göre istatiksel olarak anlamlı fark olmadığ tespit edilmiştir ( $t=0.268, p>0.05)$ ve H1a hipotezimiz reddedilmiştir. Tablo 6.'da ise duygusal empati düzeyi ortalamalarının cinsiyete göre anlamlı bir fark olduğu saptanmıştır $(\mathrm{t}=2.583$, $\mathrm{p} \leq 0.01)$ ve H1b hipotezimiz kabul edilmiştir. Buna göre k1z öğrencilerin erkek öğrencilere göre daha fazla duygusal empatiye sahip oldukları söylenebilir.

Tablo 7. Toplam Empati Düzeyinin Cinsiyete Göre Farkı

\begin{tabular}{lcccccc}
\hline \hline Gruplar & $\mathrm{N}$ & $\overline{\mathrm{X}}$ & $\mathrm{Ss}$ & $\mathrm{Sd}$ & $\mathrm{t}$ & $\mathrm{p}$ \\
\hline Kadın & 112 & 3.52 & 0.47 & \multirow{2}{*}{156} & \multirow{2}{*}{1.571} & 0.12 \\
Erkek & 46 & 3.40 & 0.38 & & & \\
\hline \hline
\end{tabular}

Tablo 8. Bilişsel, Duygusal ve Toplam Empati Düzeyinin Sınıflara Göre Farkı

\begin{tabular}{lccccc}
\hline \hline Bilişsel Empati & Kareler Toplamı & Sd & Kareler Ortalaması & F & p \\
\hline Gruplar Arası & 0,123 & 3 & 0,041 & & 0,943 \\
Gruplar İçi & 48,859 & 154 & 0,317 & 0,129 &
\end{tabular}




\begin{tabular}{lccccc}
\hline Toplam & 48,983 & 157 & & & \\
\hline $\begin{array}{l}\text { Duygusal } \\
\text { Empati }\end{array}$ & Kareler Toplamı & Sd & Kareler Ortalaması & F & $p$ \\
\hline Gruplar Arası & 1,865 & 3 & 0,622 & 0,173 \\
Gruplar İçi & 56,966 & 154 & 0,370 & 1,681 & $\mathrm{p}$ \\
Toplam & 58,831 & 157 & Kareler Ortalaması & F & 0,423 \\
\hline Toplam Empati & Kareler Toplamı & Sd & 0,190 & & 0,940 \\
\hline Gruplar Arası & 0,569 & 3 & 0,202 & \\
Gruplar İçi & 31,043 & 154 & 157 & & \\
Toplam & 31,612 & & & \\
\hline \hline
\end{tabular}

Tablo 9. Bilişsel, Duygusal ve Toplam Empati Düzeyinin Yaşa Göre Farkı

\begin{tabular}{|c|c|c|c|c|c|}
\hline Bilişsel Empati & Kareler Toplamı & $\mathrm{Sd}$ & Kareler Ortalaması & F & $\mathrm{p}$ \\
\hline Gruplar Arası & 0,447 & 3 & 0,149 & & \\
\hline Gruplar İçi & 48,535 & 154 & 0,315 & 0,473 & 0,701 \\
\hline Toplam & 48,983 & 157 & & & \\
\hline $\begin{array}{l}\text { Duygusal } \\
\text { Empati }\end{array}$ & Kareler Toplamı & Sd & Kareler Ortalaması & $\mathrm{F}$ & $\mathrm{p}$ \\
\hline Gruplar Arası & 0,582 & 3 & 0,194 & & \\
\hline Gruplar İçi & 58,249 & 154 & 0,378 & 0,513 & 0,674 \\
\hline Toplam & 58,831 & 157 & & & \\
\hline Toplam Empati & Kareler Toplamı & Sd & Kareler Ortalaması & $\mathrm{F}$ & $\mathrm{p}$ \\
\hline Gruplar Arası & 0,483 & 3 & 0,161 & & \\
\hline Gruplar İçi & 31,129 & 154 & 0,202 & 0,796 & 0,498 \\
\hline Toplam & 31,612 & 157 & & & \\
\hline
\end{tabular}

Tablo 7.'de ise öğrencilerin toplam empati düzeyleri ile cinsiyet düzeyleri arasında istatiksel olarak anlamlı bir fark bulunamamıştır. Tablo 8. ve Tablo 9.'da Öğrencilerin hem bilişsel hem duygusal hem de toplam empati ortalamalarının sınıf ve yaş düzeyleri bakımından istatiksel olarak anlamlı bir fark olmadığı tespit edilmiştir ve $\mathrm{H} 2 \mathrm{a}, \mathrm{H} 2 \mathrm{~b}, \mathrm{H} 3 \mathrm{a}$ ve $\mathrm{H} 3 \mathrm{~b}$ hipotezlerimiz reddedilmiştir.

Tablo 10. Öğrencilerin Kişilik Düzeyleri

\begin{tabular}{ccccccc}
\hline \hline \multirow{2}{*}{ Gruplar } & & Dişadönüklük & Uyumluluk & Sorumluluk & $\begin{array}{c}\text { Duygusal } \\
\text { Dengelilik }\end{array}$ & $\begin{array}{c}\text { Zekâ/Hayal } \\
\text { Gücü }\end{array}$ \\
\hline \multirow{2}{*}{ Kadin } & Ortalama & 3,24 & 3,86 & 4,02 & 3,12 & 3,73 \\
& $\begin{array}{c}\text { Frekans } \\
\text { Standart } \\
\text { Sapma }\end{array}$ & 112 & 112 & 112 & 112 & 112 \\
\hline \multirow{2}{*}{ Erkek } & Ortalama & 3,61 & 0,41 & 0,55 & 0,81 & 0,50 \\
& $\begin{array}{c}\text { Frekans } \\
\text { Standart }\end{array}$ & 46 & 3,78 & 3,92 & 2,71 & 3,86 \\
\hline \multirow{2}{*}{ Toplam } & Sapma & 0,60 & 46 & 46 & 46 & 46 \\
& Ortalama & 3,26 & 0,46 & 0,60 & 0,71 & 0,53 \\
\hline
\end{tabular}




$\begin{array}{cccccc}\text { Frekans } & 158 & 158 & 158 & 158 & 158 \\ \begin{array}{c}\text { Standart } \\ \text { Sapma }\end{array} & 0,61 & 0,43 & 0,56 & 0,80 & 0,51\end{array}$

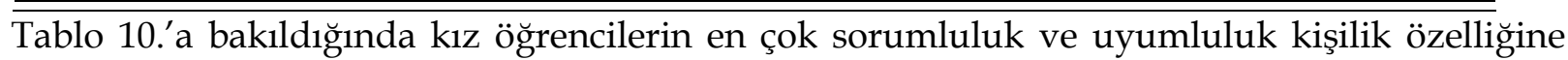
sahip olduğu görülmektedir. Erkek öğrencilerin ise en çok sorumluluk ve zekâ/hayal gücü kişilik özelliği gösterdikleri tespit edilmiştir. Aşağıda Tablo 11.'de ise öğrencilerin empati düzeyleri ile kişilik özellikleri arasındaki ilişki düzeyleri sunulmuştur.

Tablo 11. Öğrencilerin Empati Düzeyleri ile Kişilik Özellikleri Arasındaki İlişki

\begin{tabular}{|c|c|c|c|c|c|c|}
\hline \multicolumn{2}{|l|}{ Gruplar } & \multirow{2}{*}{$\begin{array}{c}\text { Dişadönüklük } \\
.192\end{array}$} & \multirow{2}{*}{$\begin{array}{c}\text { Uyumluluk } \\
.366^{* *}\end{array}$} & \multirow{2}{*}{$\begin{array}{c}\text { Sorumluluk } \\
.253^{*}\end{array}$} & \multirow{2}{*}{$\begin{array}{c}\begin{array}{c}\text { Duygusal } \\
\text { Dengelilik }\end{array} \\
.041\end{array}$} & \multirow{2}{*}{$\begin{array}{c}\begin{array}{c}\text { Zekâ/Hayal } \\
\text { Gücü }\end{array} \\
370^{* *}\end{array}$} \\
\hline Bilissel & $\mathrm{r}$ & & & & & \\
\hline Empati & $\mathrm{p}$ & .015 & $.000^{*}$ & $.001^{*}$ & .612 & $.000^{* *}$ \\
\hline Duygusal & $\mathrm{r}$ & .078 & $.279^{* *}$ & .003 & $.366^{* *}$ & -.110 \\
\hline Empati & $\mathrm{p}$ & .328 & $.000^{* *}$ & .967 & $.000^{* *}$ & .171 \\
\hline Toplam & $\mathrm{r}$ & .173 & $.418^{* *}$ & .160 & $.275^{* *}$ & .156 \\
\hline Empati & $\mathrm{p}$ & .030 & $.000^{* *}$ & .045 & $.000^{* *}$ & .051 \\
\hline
\end{tabular}

r: Pearson Korelasyon Katsayısı; p: anlamlılık düzeyi; * $\mathrm{p}=.01$ anlamlılık düzeyi, ${ }^{* *} \mathrm{p}<.01$ anlamlılık düzeyi

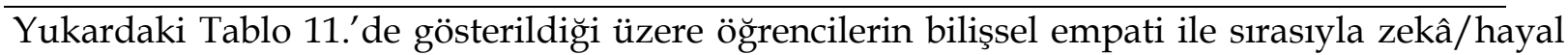
gücü $(\mathrm{r}=.370 ; \mathrm{p}=.000)$ ve uyumluluk $(\mathrm{r}=.366, \mathrm{p}=.000)$ kişilik özellikleri arasında orta düzeyde, sorumluluk $(\mathrm{r}=.253, \mathrm{p} \leq .01)$ kişilik özelliği arasında ise zayıf ve pozitif yönlü anlamlı bir ilişki olduğu tespit edilmiştir. Bu sonuca göre $\mathrm{H} 4 a$ hipotezimiz kabul edilmiştir. Öğrencilerin duygusal empati ile duygusal dengelilik $(\mathrm{r}=.0366, \mathrm{p}=.000)$ kişilik özelliği arasında orta düzeyde ve uyumluluk $(\mathrm{r}=.279$, $\mathrm{p}=.000)$ kişilik özelliği arasında zayıf ve pozitif yönlü anlamlı bir ilişki olduğu saptanmıştır. Buna göre $\mathrm{H} 4 \mathrm{~b}$ hipotezimiz kabul edilmiştir. Öğrencilerin toplam empatileri ile uyumluluk $(\mathrm{r}=.418$, $\mathrm{p}=.000)$ kişilik özelliği arasında orta düzeyde ve duygusal dengelilik ( $\mathrm{r}=.275, \mathrm{p}=.000)$ kişilik özelliği arasında zayıf ve pozitif yönlü anlamlı bir ilişki olduğu tespit edilmiştir.

\section{Sonuç ve Değerlendirme}

Demografik değişkenlerden cinsiyet değişkeni incelendiğinde araştırmamızın \%70,9'unu kız öğrenciler (112 kişi) ve \%29,1'ini ise erkek öğrenciler oluşturmaktadır. Kız öğrencilerin erkek öğrencilerden fazla olmasının nedeni bölüm tercihinde kız öğrencilerin ağırlıkta olmasıdır. Yaş değişkeni bakımından öğrencilerin \%91'1'i 20 yaş ve üzerindedir (144 kişi). Öğrencilerin sınıfları bakımından incelendiğinde ise $1 .(\% 24,7), 2$. (\%25,9), 3. (\%26,6) ve 4. $(\% 22,8)$ sinıfta öğrenim gören öğrencilerin dengeli dağıldığı görülmektedir. Öğrencilerin empati düzeylerinde ise bilişsel empati ortalamalarının hem kız öğrencilerde $(\bar{x}=3.78)$ hem de erkek öğrencilerde ( $\bar{x}=3.81)$ yüksek düzeyde olduğu söylenebilir. Fakat duygusal empati ortalamalarının kız öğrencilerde ( $\bar{x}=3.26)$ ve erkek öğrencilerde ( $\bar{x}=2.99$ ) orta düzeye yakın olduğu saptanmıştır. Her ne kadar duygusal empati ortalamaları bilişsel empati ortalamalarına göre her iki cinsiyette de düşük olsa da toplam empati ortalamaları orta düzeyin üzerinde olduğu tespit edilmiştir (kız öğrenciler toplam empati $\bar{x}=3.52$ ve erkek öğrenciler toplam empati $\bar{x}=3.40$ ). Williams vd. (2020)'ne göre bilişsel empati ne kadar yüksek olursa olsun mağdurda herhangi bir olumsuz durum oluşturmamaktadır. Fakat duygusal empatinin çok yüksek olması mağdurda olumsuz durumlara sebep olup şefkat yorgunluğuna ve tükenmişliğe yol açabilir. Buna göre duygusal empatinin sağlık çalışanlarında çok yüksek olmaması beklenmektedir. Bu çıkan sonuç Williams vd. (2020)'nin görüşü ile paralellik göstermektedir. Cinsiyete göre empati düzeylerinde fark olup olmadığı incelendiğinde bilişsel empati ve toplam empati ortalamalarında istatiksel olarak anlamlı bir fark çıkmamıştır. Ancak duygusal empati ortalamalarında $\mathrm{p} \leq .01$ anlamlılık düzeyinde istatiksel olarak bir fark olduğu ve kız öğrencilerin erkek öğrencilere göre daha fazla duygusal empatiye sahip oldukları tespit edilmiştir. Bu farkın 
çıkmasında yaratılış gereği kadınların erkeklere göre daha duygusal yapıda olması etkili olabilir. Genel empati puanları toplamında istatiksel olarak anlamlı fark çıkmasa da kız öğrencilerin ortalamalarının ( $\bar{x}=3.52)$ erkek öğrencilerin ortalamalarından $(\bar{x}=3.40)$ daha yüksek olduğu görülmektedir. Bu çıkan sonuç ise literatürde cinsiyete göre kadınların daha empatik olduğu görüşünü desteklemektedir (Hojat vd., 2005; Abe vd. 2018; Baron-Cohen ve Wheelwright, 2004). Sınıf ve yaş düzeyleri açısından ise empati ortalama puanları arasında istatiksel olarak anlamlı bir fark bulunamamıştır.

Öğrencilerin kişilik özellikleri incelendiğinde ise kız öğrencilerin daha çok sorumluluk ( $\bar{x}=4.02)$ ve uyumluluk ( $\bar{x}=3.86$ ) kişilik özelliklerine sahip oldukları görülmektedir. Erkek öğrencilerin ise daha çok sorumluluk ( $\bar{x}=3.92)$ ve zekâ/hayal gücü ( $\bar{x}=3.86)$ kişilik özelliklerine sahip oldukları tespit edilmiştir. Sorumluluk kişilik özelliğine sahip insanlar işlerinde özenli ve planlıdırlar. Ayrıca düzeni de seven kişilerdir. Bu kişilik özelliğine sahip olan öğrenciler arama kurtarma faaliyetlerinde daha özverili ve daha bilinçli müdahaleler gerçekleştirebilir. Bu sonuca göre bu kişilik özelliğine sahip öğrencilerin diğer kişilik özelliğine sahip öğrencilere göre arama-kurtarma çalışmalarında daha sistemli olması beklenebilir. Uyumluluk kişilik özelliğine sahip insanlar duyguları hisseden ve paylaşan, yumuşak huylu, yardımsever kişilerdir. Kız öğrencilerin ise uyumluluk kişilik özelliği ortalamalarının yüksek olması kadınların daha merhametli, paylaşımcı, ilgili ve duygusal yapıya sahip olması ile paralellik göstermektedir. Aynı zamanda duygusal empatilerin erkeklere göre daha yüksek olması da bu kişilik özelliğini desteklemektedir ve müdahalelerde daha makul bir duygusal empati sergileyebilirler. Zekâ/hayal gücü kişilik özelliğine sahip kişiler ise fikirlere açık, hayal gücü kuvvetli, olaylar üzerinde düşünen ve çözüm odaklı kişilerdir. Bu kişilik özelliğine sahip öğrencilerin diğer kişilik özelliğine sahip öğrencilere kıyasla bilişsel empatilerini geliştirmeleri daha muhtemeldir. Ayrıca arama-kurtarma çalışmalarında daha iyi fikirler üreterek iyi sonuç verebilecek çeşitli müdahale yöntemleri gerçekleştirebilirler.

Kişilik özellikleri ile empati arasında ilişki incelendiğinde ise Pearson korelayon testi sonucuna göre, bilişsel empati ile zekâ/hayal gücü $(\mathrm{r}=.370, \mathrm{p}=.000)$ ve uyumluluk $(\mathrm{r}=.366, \mathrm{p}=.000)$ kişilik özellikleri arasında orta düzeyde pozitif yönlü ilişki vardır. Sorumluluk $(r=.253, p \leq .01)$ kişilik özelliği arasında ise düşük düzeyde pozitif yönlü ilişki vardır. Bu sonuca göre uyumlu, hayal gücü kuvvetli ve sorumlu öğrencilerin daha çok bilişsel empatiye sahip olma eğiliminde oldukları söylenebilir. Duygusal empati ile duygusal dengelilik $(\mathrm{r}=.366, \mathrm{p}=.000)$ kişilik özelliği arasında orta düzey, uyumluluk $(r=.279, p=.000)$ arasında ise zayıf ve pozitif yönlü anlamlı bir ilişki saptanmıştır. Bu sonuca göre duygusal dengeliliğe sahip ve uyumlu öğrencilerin daha çok duygusal empatiye sahip olma eğiliminde oldukları söylenebilir. Öğrencilerin genel empatileri ile uyumluluk ( $\mathrm{r}=.418$, $p=.000$ ) kişilik özelliği arasında orta düzeyde ve pozitif yönlü anlamlı bir ilişki olduğu bulunmuştur. Bu sonuç literatürde desteklenmektedir (Nettle, 2007; Mooradian vd., 2011; Magalhães vd., 2012; Costa vd., 2014; Melchers vd., 2016; Abe vd., 2018). Ayrıca duygusal dengelilik $(r=.275, p=.000)$ kişilik özelliği ile de zayıf ve pozitif yönlü anlamlı bir ilişki olduğu belirlenmiştir. Literatür çalışmalarında kullanılan bazı kişilik ölçeklerinde duygusal dengelilik yerine tersi olan nevrotiklik kişilik özelliği baz alınmıştır. Buna göre literatür çalışmalarında nevrotiklik kişilik özelliği ile empati arasında tespit edilen ilişkinin çalışmamız da çıkan sonucunu desteklediğini söyleyebiliriz (Daane ve Schmidt, 1957; Hojat vd., 2005; Mooradian vd., 2011).

Yapılan bu çalışma örneklem ve ana kütle olarak sadece Gümüşhane ilinde faaliyet gösteren Gümüşhane Üniversitesi Acil Yardım ve Afet Yönetimi bölümünde öğrenim gören öğrencileri kapsamaktadır. Dolayısı ile sonuçlar ülke genelini kapsamayacaktır. Yine de çıkan bu sonuçlar Gümüşhane Üniversitesi öğrencilerinin kişilik özellikleri ve empati seviyeleri hakkında bilgi vermektedir. İlerde yapılacak çalışmalarda gerek örneklemin büyüklüğ̈ü gerekse örneklem seçiminde rassal yöntemlerden birinin kullanılması ile daha kapsamlı sonuçlar elde edilebilir. Örneklem olarak AFAD (Afet ve Acil Durum Yönetimi Başkanlığı), UMKE (Ulusal Medikal Kurtarma Ekipleri), AKUT (Arama Kurtarma Derneği), SITTAP (Sivil Toplum Afet Platformu), AKA (Arama Kurtarma Araştırma Derneği) gibi kuruluşların arama ve kurtarma faaliyetinde bulunan çalışanları seçilerek yeni araştırmalar yapılabilir. Ayrıca yapılacak çalışmalarda sempati kavramının yanı sıra Morse'nun Empati Bileşenlerinden ahlaki ve davranışsal empatisi de eklenerek farklı 
sonuçlar elde edilebilir. Empatinin doğuştan geldiği ve sonradan da geliştirilebildiği daha önceki çalışmalarda tespit edilmiştir. Bu bağlamda mesleki hayatlarında mağdur kişilere yardım edeceği beklenen öğrencilerin özellikle bilişsel empatileri geliştirilerek daha verimli müdahale ve yöntemler gerçekleştirmeleri sağlanabilir.

\section{Kaynakça}

Abe, K., Niwa, M., Fujisaki, K., ve Suzuki, Y. (2018). Associations between emotional intelligence, empathy and personality in Japanese medical students. BMC medical education, 18(1), 1-9.

Allport, G. W. ve Odbert, H. S. (1936). Trait-names: A psycho-lexical study.Psychological monographs, 47(1), i-171.

Baron-Cohen, S., ve Wheelwright, S. (2004). The empathy quotient: an investigation of adults with Asperger syndrome or high functioning autism, and normal sex differences. Journal of autism and developmental disorders, 34(2), 163-175.

Bas-Sarmiento, P., Fernández-Gutiérrez, M., Baena-Baños, M., Correro-Bermejo, A., Soler-Martins, PS ve de la Torre-Moyano, S. (2020). Sağlık bilimlerinde empati eğitimi: Sistematik bir inceleme. Uygulamada Hemşire Eğitimi , 102739, 1-13.

Bellet, P. S., ve Maloney, M. J. (1991). The importance of empathy as an interviewing skill in medicine. Jama, 266(13), 1831-1832.

Buie, D. H. (1981). Empathy: Its nature and limitations. Journal of the American Psychoanalytic Association, 29(2), 281-307.

Cattell, R. B. (1947). Confirmation and clarification of primary personality factors.Psychometrika, 12(3), 197-220.

Coplan, A. (2011). Will the real empathy please stand up? A case for a narrow conceptualization. The Southern Journal of Philosophy, 49, 40-65.

Costa Jr, P. T. ve McCrae, R. R. (2008). The Revised NEO Personality Inventory (NEOPI-R). Sage Publications, Inc.

Costa, P., Alves, R., Neto, I., Marvao, P., Portela, M., ve Costa, M. J. (2014). Associations between medical student empathy and personality: a multi-institutional study. PloS one, 9(3), e89254.

Cuff, B. M., Brown, S. J., Taylor, L., \& Howat, D. J. (2016). Empathy: A review of the concept. Emotion review, 8(2), 144-153.

Daane, C. J., ve Schmidt, L. G. (1957). Empathy and personality variables. The Journal of Educational Research, 51(2), 129-135.

Decety, J., ve Jackson, P. L. (2004). The functional architecture of human empathy. Behavioral and cognitive neuroscience reviews, 3(2), 71-100.

Duan, C., ve Hill, C. E. (1996). The current state of empathy research. Journal of counseling psychology, 43(3), 261-274.

Dymond, R. F. (1950). Personality and empathy. Journal of Consulting Psychology, 14(5), 343-350.

Erlanger, A. C. E., ve Tsytsarev, S. V. (2012). The relationship between empathy and personality in undergraduate students' attitudes toward nonhuman animals. Society \& Animals, 20(1), 21-38.

Elliott, R., Bohart, A. C., Watson, J. C., \& Greenberg, L. S. (2011). Empathy. Psychotherapy, 48(1), 4349.

Goldberg, L. R. (1990). An alternative" description of personality": the big-five factorstructure. Journal of personality and social psychology, 59(6), 1216.

Greenberg, L. S., Watson, J. C., Elliot, R., ve Bohart, A. C. (2001). Empathy. Psychotherapy: Theory, research, practice, training, 38(4), 380-384.

Hojat, M., Zuckerman, M., Magee, M., Mangione, S., Nasca, T., Vergare, M., ve Gonnella, J. S. (2005). Empathy in medical students as related to specialty interest, personality, and perceptions of mother and father. Personality and Individual Differences, 39(7), 1205-1215.

Magalhães, E., Costa, P., ve Costa, M. J. (2012). Empathy of medical students and personality: evidence from the Five-Factor Model. Medical Teacher, 34(10), 807-812. 
Melchers, M. C., Li, M., Haas, B. W., Reuter, M., Bischoff, L., \& Montag, C. (2016). Similar personality patterns are associated with empathy in four different countries. Frontiers in psychology, 7(290), $1-12$.

Mercer, S. W., ve Reynolds, W. J. (2002). Empathy and quality of care. British Journal of General Practice, 52(Suppl), S9-12.

Montazeri, M., Tagharrobi, Z., Sooki, Z., ve Sharifi, K. (2020). Development and psychometric evaluation of the Hospital Nurse Interpersonal Empathy Questionnaire. International journal of nursing sciences, 7(3), 337-343.

Mooradian, T. A., Davis, M., ve Matzler, K. (2011). Dispositional empathy and the hierarchical structure of personality. The American journal of psychology, 124(1), 99-109.

Nettle, D. (2007). Empathizing and systemizing: what are they, and what do theycontribute to our understanding of psychological sex differences? Br. J. Psychol.98, 237-255.

Norman, W. T. (1963). Toward an adequate taxonomy of personality attributes:Replicated factor structure in peer nomination personality ratings. The Journal of Abnormal and Social Psychology, 66(6), 574.

Stueber, K. (2013). Empathy. International Encyclopedia of Ethics.1-8.

Thurstone, L. L. (1934). The vectors of mind. Psychological review, 41(1), 1-32.

Vossen, H. G., Piotrowski, J. T., \& Valkenburg, P. M. (2015). Development of the adolescent measure of empathy and sympathy (AMES). Personality and Individual Differences, 74, 66-71.

Williams, C. R., Rodgers, P. T., McLaughlin, J. E., Angelo, T. A., ve Shepherd, G. (2020). Comparing Empathy Levels in Doctor of Pharmacy Students and Exemplary Pharmacist Preceptors. American Journal of Pharmaceutical Education, 84(3).

\section{Aim and Scope}

\section{Extended Abstract}

The aim of this study is to determine the empathy levels of the students studying in the Emergency Aid and Disaster Management department, who are expected to engage in search and rescue activities in their future lives, and the relationship between their personality traits and their empathy levels. The importance of the research is that individuals with personality structure compatible with empathic behavior may be preferred in the selection of the personnel to perform search and rescue activities. In addition, empathic behaviors of personnel who have personality traits that are not related to empathy can be improved with empathy training.

\section{Methods}

The convenience sampling method was used in our study. The total of day and night students studying in the Emergency Aid and Disaster Management Department of Gümüşhane University is 409. A survey was conducted with 158 students whom we could reach with the help of social media tools. In the completed questionnaires, incomplete and error was not detected. All answers are included in the analysis. In our research, Vossen et al. the cognitive and emotional empathy scale part of the Empathy and Sympathy in Adolescents Scale (AMES) developed by (2015) was used. 4 questions measure cognitive empathy and 4 questions measure emotional empathy. As the personality scale, the Five-Factor Personality Scale with 42 items, adapted by Oyanik (2020), was used. The questionnaires have been delivered to individuals via social media tools and consist of 3 parts. In the first part, demographic features were tried to be measured with categorical questions (3 questions), in the second part empathy levels were tried to be measured with 5 Likert type questions (8 questions) and in the third part personality traits were measured with 5 Likert type questions (25 questions).

\section{Findings}

When the gender variable, one of the demographic variables, is examined, $70.9 \%$ of our study is female students ( 112 people) and $29.1 \%$ are male students. The reason why female students are more than male students is that female students predominate in the choice of department. In terms of age variable, $91 \%$ of the students are 20 years and over (144 people). When the students are examined in terms of their classes, it is seen that the students studying in 1st $(24.7 \%)$, 2nd (25.9\%), 3rd (26.6\%) 
and 4th (22.8\%) classes are distributed in a balanced way. In the empathy levels of the students, it can be said that the cognitive empathy averages are high in both female students $(\square \mathrm{x}=3.78)$ and male students ( $\square \mathrm{x}=3.81$ ). However, the average emotional empathy was found to be close to the middle level in female students $(\square \mathrm{x}=3.26)$ and male students $(\square \mathrm{x}=2.99)$. Although the emotional empathy averages were lower in both genders than the cognitive empathy averages, it was found that the total empathy averages were above the middle level (female students total empathy $=\mathrm{x}=$ 3.52 and male students total empathy $\square \mathrm{x}=3.40$ ). Williams et al. According to (2020), no matter how high the cognitive empathy is, it does not create any negative situation in the victim. However, when emotional empathy is too high, it can cause negative situations in the victim and lead to compassion fatigue and burnout. Accordingly, emotional empathy is not expected to be very high in healthcare workers. This result is parallel with Williams et al. (2020) 's opinion. When it was examined whether there is a difference in empathy levels according to gender, there was no statistically significant difference in cognitive empathy and total empathy averages. However, it was determined that there is a statistically significant difference in the mean emotional empathy at the level of significance $p \leq .01$ and female students have more emotional empathy than male students. The fact that women have a more emotional structure compared to men by nature may be effective in the emergence of this difference. Although there is no statistically significant difference in the overall empathy scores, it is seen that the mean of my female students $(x=3.52)$ is higher than the mean of male students $(\square \mathrm{x}=3.40)$. This result supports the view in the literature that women are more empathetic compared to gender (Hojat et al., 2005; Abe et al.2018; Baron-Cohen \& Wheelwright, 2004). There was no statistically significant difference between the average empathy scores in terms of grade and age levels.

When the personality traits of the students are examined, it is seen that the female students have more responsibility $(\mathrm{x}=4.02)$ and compatibility $(\mathrm{x}=3.86)$ personality traits. It was determined that male students have more responsibility $(x=3.92)$ and intelligence / imagination $(x=3.86)$ personality traits. People with the personality trait of responsibility are attentive and planned in their work. They are also people who love order. Students with this personality trait can make more self-sacrificing and more conscious interventions in search and rescue activities. According to this result, it can be expected that students with this personality trait will be more systematic in search and rescue activities than students with other personality traits. People with the adaptive personality trait are mild-tempered, helpful people who feel and share emotions. The higher average compatibility personality trait of female students is in parallel with the fact that women have more compassionate, sharing, caring and emotional structures. At the same time, higher emotional empathy than men also supports this personality trait and they may have better emotional empathy in interventions. On the other hand, people with intelligence / imagination personality traits are open to ideas, strong imagination, thinking about events and being solution-oriented. Students with this personality trait can develop various intervention methods that can give good results by producing better ideas in search and rescue activities.

When the relationship between personality traits and empathy was examined, according to the result of the Pearson correlation test, cognitive empathy and intelligence / imagination $(r=.370, p$ $=.000)$ and compatibility $(\mathrm{r}=.366, \mathrm{p}=.000)$ There is a positive relationship. There is a low level positive relationship between responsibility $(\mathrm{r}=.253, \mathrm{p} \leq .01)$ personality trait. According to this result, it can be said that harmonious, imaginative and responsible students tend to have more cognitive empathy. A moderate relationship was found between emotional empathy and emotional stability $(\mathrm{r}=.366, \mathrm{p}=.000)$, and a weak and positive correlation was found between compatibility $(\mathrm{r}$ $=.279, \mathrm{p}=.000)$. According to this result, it can be said that emotionally balanced and compliant students tend to have more emotional empathy. It was found that there is a moderate and positive significant relationship between students' general empathy and compatibility $(\mathrm{r}=.418, \mathrm{p}=.000)$ personality trait. This result is supported in the literature (Nettle, 2007; Mooradian et al., 2011; Magalhães et al., 2012; Costa et al., 2014; Melchers et al., 2016; Abe et al., 2018). In addition, emotional stability $(\mathrm{r}=.275, \mathrm{p}=.000)$ was found to be a weak and positive significant relationship with personality trait. In some personality scales used in literature studies, the opposite of neuroticism 
personality traits were used instead of emotional stability. Accordingly, we can say that the relationship detected between neuroticism personality trait and empathy in lithotripsy studies supports the result of our study (Daane \& Schmidt, 1957; Hojat et al., 2005; Mooradian et al., 2011).

\section{Conclusion}

When emotional empathy levels were examined, it was found that there was a difference according to gender and that female students had a higher average than male students. When the correlation between personality traits and empathy levels was examined, it was found that there was a moderate correlation between cognitive empathy and intelligence / imagination and compatibility personality trait, and a low level of significant and positive correlation between responsibility personality trait. It was found that there was a moderate correlation between emotional empathy and emotional stability personality trait, and a low level of significant and positive correlation also with the compatibility personality trait. 